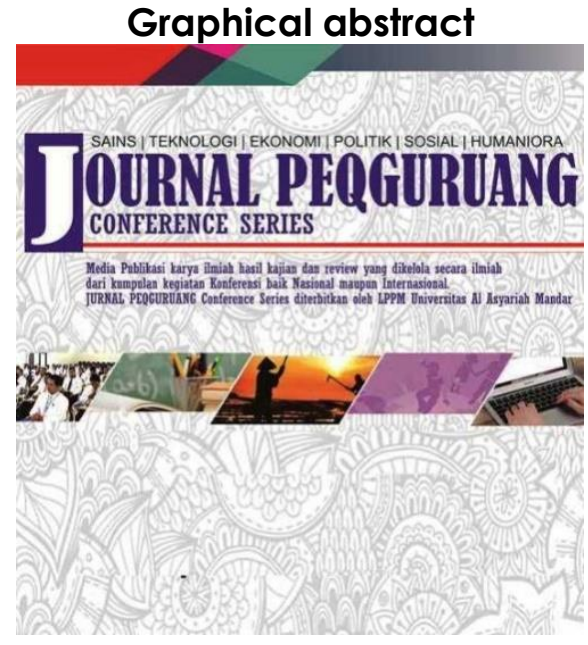

\title{
EFEKTIVITAS METODE OUTDOOR LEARNING TERHADAP KEMAMPUAN MENULIS PUISI PADA PESERTA DIDIK KELAS X SMK NEGERI BULO
} \author{
Polewali Mandar \\ *Corresponding author \\ 1rahmasegerang@gmail.com, \\ ${ }^{2}$ muthmainnahunasman@gmail.com, \\ 3hafsahnur.iswaka@yahoo.co.id
}

${ }^{1 *}$ Rahmawati, ${ }^{2}$ Muthmainnah, ${ }^{3}$ Nur Hafsah Yunus Universitas Al Asyariah Mandar, Jl. Budi Utomo No.

\begin{abstract}
The purpose of this was to determine the effectivenes of outdoor learning methodson the ability to write poetry in grade X grade students of SMK Negeri Bulo. This is type of research is a type of research is a type of pure experimental research using one experimental class using the outdoor learning method and the control class without using the outdoor learning method. As for the population of this study were all students of class X SMK Negeri Bulo which consisted of 107 people divided into 4 class namely 25 class X APHP 1 and 25 class APHP 2, TSM a many 20 people and $\mathrm{X}$ Multimedia a many 37 people. The research instrumen used to collect data in this study was a non test. The is used to collect data about the ability to write poetry, non test instrumens in the form of observasion sheets. Based on the results of data analysis shows that the average value of the two groups has reached more than the KKM value in vocational high school Bulo. The difference in learning outcomes between the two groups show that the use of outdoor learning methods is more efective in proving students poetry writing skills than conventional methods.
\end{abstract}

Keywords: effetivity, outdoor learning methods, writing poetry

\begin{abstract}
Abstrak
tujuan penelitian ini adalah untuk mengetahui efektivitas metode outdoor learning terhadap kemampuan menulis puisi pada peserta didik kelas X SMK Negeri Bulo. Jenis penelitian ini adalah jenis peenltian eksperimen murni menggunakan satu kelas eksperimen menggunakan metode outdoor learning. Adapu populasi dari penelitian ini adalah seluruh peserta didik kelas X SMK Negeri Bulo terdiri dari 107 orang yang terbagi dalam 4 kelas yakni peserta didik kelas X APHP 1 sebanyak 25 dan kelas X APHP 2 sebanyak 25 dan kelas X TSM sebanyak 20 orang sedangkan kelas X Multimedia sebanyak 37 orang. Instrumen penelitian yang digunakan untuk mengumpulkan data tentang kemampuan menulis puisi, instrumen berupa non test berupa angket respon. Berdasarkan hasil analisis data menunjukkan bahwa nilai rata-rata kedua kelompok telah mencapai lebih dari nilai KKM yang ada di SMK Negeri Bulo perbedaan hasil belajar kedua kelompok menunjukkan bahwa penggunaan metode outdoor learning. Lebih efektif dalam meningkatkan kemampuan menulis puisi peserta didik dibandingkan metode konvensial.

Kata kunci: Efektivitas, Metode Outdoor Learning, Menulis Puisi.
\end{abstract}

Article history

DOI: http://dx.doi.org/10.35329/ip.v2i2.1611

Received : 11 September 2020 | Received in revised form : 21 September 2020 | Accepted : 09 Oktober 2020 


\section{PENDAHULUAN}

Pada suatu pembelajaran bahasa indonesia tidak sekedar ilmu atau pengetahuan bahasa saja, akan tetapi merupakan diri dari pemakai sejalan pada sosial budaya akademik dan pembelajaran karakter, pengajaran merupakan suatu jalan tidak bisa dilepas dari hidup manusia, dikarenakan proses belajar adalah sebuah hal yang paling penting dan wajib dijalani supaya lebih terara ketika menjalani kehidupan. (Tarigan 2013)

Bahasa merupakan sarana atau alat yang dipakai setiap orang pada kehidupan sehari-hari. Bahasa dapat juga disebut sebagai ucapan dari hasil alat ucap seseorang sebagai lambang bunyi yang bersifat mana suka dan mempunyai arti yang kompleks. (Dalman, 2016)

Pada dasarnya pengajaran bahasa adalah belajar berinteraksi, dikarenakan bahasa adalah wadah komunikasi pada masyarakat (Arikunto 2010). Agar berinteraksi dengan sangat baik, jadi perlu belajar sistem berbahasa yang baik dan benar.

Pengajaran akan lebih baik jika dipelajari dari awal dan berkelanjutan. Kemudian, pengajaran bahasa diikutkan pada kurikulum 2013. Salah satu kelebihan kurikulum 2013 ialah menempatkan bahasa sebagai penghela ilmu dan pengetahuan (Mahsun, 2014)

Dalam keterampilan berbahasa kemampuan menulis lebih sukar dikuasai oleh pembelajar bahasa sebab kemampuan menulis mengkehendaki penguasaan beberapa aspek lain diluar bahasa, guna menciptakan tulisan yang indah. Menurut Wikanengsih (2013) bahwa keterampilan menulis memiliki hubungan dengan daya nalar seseorang.

Keterampilan menulis dalam pembelajaran adalah suatu hal yang penting. Hal ini seperti yang diungkap oleh Tarigan (2008:3) bahwa keterampilan menulis berfungsi sebagai alat komunikasi secara tatap muka dengan orang lain. Dalam kegiatan menulis ini, penulis harus terampil memanfaatkan grafologi, struktur bahasa dan kosa kata. Selai itu, keterampilan menulis ini tidak akan datang secara otomatis, tetapi harus melalui latihan dan praktik yang banyak dan teratur. Namun, dalam praktiknya disekolah masih belum dimaksimalkan khususnya pembelajaran menulis puisi.

Menulis adalah salah satu cara yang digunakan untuk berkomunikasi secara tidak langsung tetapi melalui bahasa tulis guna menyampaikan informasi, ide ataupun gagasan kepada orang lain. Alwi (2012:121) menyatakan menulis adalah melahirkan pikiran atau perasaan dengan tulisan.

Dalam pelaksanaannya, pembelajaran menulis puisi belum sejatinya berjalan dengan lancar baik. Tetapi pada kenyataannya yang pengajaran menulis puisi masih dalam tahap teori puisi, nama pengarang, dan yang lain. Pengarang menulis puisi disekolah masih banyak hambatan dan terkadang dihindari. Hambatan dalam pengajaran menulis, antarannya terbatasnya waktu yang disediakan, minimnya alat dan juga bahan, kemauan peserta didik masih rendah dalam menulis puisi, dan jam pembelajaran bahasa indonesia ditaruh pada jam terakhir. Hal tersebut tidak mendkung pada kegiatan pengajaran.

Berdasarkan fakta dilapangan didapati bahwa pada proses pengajaran menulis puisi peserta didik masih banyak mengalami kesusahan. Selama peserta didik susdah dalam menerapkan ide atau gagasan yang dimiliki dalam bentuk puisi. Gagasan itu biasanya masih tidak tersusun dengan jelas hingga penjelasannya kurang jelas. rintangan yang diperoleh peserta didik pada pengajaran menulis dihasilkan dari cara pengajaran menulis dihasilkan dari cara pengajaran yang dipakai guru kurang menarik sebagai bagi peserta didik. Hal ini dikarenakan oleh banyak faktor, antaranya penggunaan metode pada proses pengajaran yang bervariasi, guru masih kadang memakai cara yang konvensioanal pada pengajaran akibatnya membuat peserta didik merasa malas, jenuh, dan tidak bisa membangkitkan motivasi atau munat peserta didik dalam mengikut pengajaran tersebut. Peserta didik merasa pengajaran menulis puisi membosankan akibatnya menjadikan peserta didik tidak terlalu suka untuk data memperoleh karya secara maksimal selain itu, Peserta didik banyak yang tidak terlalu percaya pada diri untuk menunjukkan hasil karyanya kepada orang lain.

Kejadian itu pula terjadi dalam pengajaran menulis puisi dalam peserta didik kelas X SMK Negeri Bulo. Peserta didik dikelas ini kurang termotivasi untuk mengikuti pembelajaran menulis puisi karena metode yang digunakan guru hanya metode ceramah teoritis yang tidak membangkitkan semangat peserta didik dan contoh puisi yang ditunjukkan hanya pada buku teks pegangan peserta didik, bahkan tidak menjelaskan langkah-langkah menulis puisi. Cara pembelajaran seperti itu tentunya membingungkan peserta didik, dan peserta didik pun kurang tertarik mengikuti pembelajaran tersebut. Dalam komponen pembelajaran, cara mengajar guru, termasuk didalamya penggunaan metode pembelajaran, sangat penting demi pembelajaran tersebut. Oleh karena itu, metode pembelajaran yang efektif sebaiknya diterapkan dalam pelaksanaan pembelajaran.

\section{TINJAUAN PUSTAKA}

Kegiatan pembelajaran bahasa indonesia dengan pembelajaran menulis, seesorang peserta didik bisa memerlukan kemampuannya untuk menggunakan bahasa yang bagus dan baik dengan melalui proses berpikir, biar bahasa yang digunakan lebih gampang dipahami bagi orang lain. Tulisan yang baik ialah tulisan dengan bentuk yang singkat, akan tetapi mudah dimengerti.

Kemampuan kesanggupan, kecakapan, kekuatan. Sdeangkan pengertian menulis ialah membuat huruf (angka dsb) dan pena, (pensil, kapur, dsb), untuk melahirkan pikiran atau perasaan seperti mengarang membuat surat dengan tulisan. (Tarigan 2008: 21) 
menyatakan bahwa menulis adalah menurunkan atau menggambarkan lambang-lambang grafik itu.

Zainurrahman (2011: 5) mengemukakan bahwa menulis dalam konteks formal merupakan aktivitas berbahasa yang paling fleksibel. Artinya menulis memiliki struktur wajib yang tidak boleh diubah secara teratur.

Rendahnya kemampuan menulis merupakan masalah tersendiri dalam pembelajaran bahasa indonesia, banyak faktor yang menjadi penyebab diantaranya melalui pembelajaran yang kurang aktif. (Muthmainnah, 2016).

Orang yang dimaksud ialah seorang pembaca yang bisa memahami bahasa dengan benar ketika menggunakan keterampilannya. Dan keterampilan tersebut tidak harus dengan tiba-tiba, melainkan melalui kebiasaan secara menyeluruh. Ketika dilihat dari keterampilan cara menggunakan bahasa saat menulis ialah kegiatan yang aktif secara dengan kebiasaan. Tarigan (2008:21) menyatakan bahwa penulis adalah membawakan dengan menggambarkan lambang grafik dengan suatu bahasa yang telah dipahami orang lain.

\section{METODE PENELITIAN}

Penelitian merupakan salah satu bentuk mencari tahu pemebenaran atau ilmu pengetahuan yang sigatnya ilmiah melalui struktur yang telah disepakati, untuk mencapai kebenaran yang hakiki. Secara sistematis, penggunaan metode ilmiah memerlukan suatu kerangka atau perencanaan. Karena pada penelitian ini adalah penelitian yang dilakukan dilapangan dan membutuhkan penganalisian statistik (data yang berupa angka) untuk kebenaran apa yang diketahui, maka dalam penelitian ini disebut sebagai penelitian kualitatif dan kuantitati, kuantitatif adalah penelitisn yang berupa angka untuk mengetahui apa yang tida diketahui sebelumnya.

Tempat dan Waktu Penelitian

1. Tempat Penelitian

Penelitian ini dilakukan pada peserta didik siswa kelas X SMK Negeri Bulo Kabupaten Polewali Mandar tahun ajaran 2019/2020 yang merupakan satu salah sekolah yang ada di Kabupaten Polewali Mandar.

2. Waktu Penelitian

Pelaksanaan penelitian ini berlangsung selama 2 bulan lamanya dimulai dari bulan Februari sampai dengan Maret 2020. Waktu kegiatan penelitian ini di Sekolah Menengah Kejuruan Negeri Bulo kabupaten Polewali Mandar

Instrumen Penelitian

1. Tes

Tes adalah salah satu atau teknik pengumpulan data dengan memberikan beberapa pernyataan guna mendapatkan info yang diteliti. Tes ini dipakai pada dua kondisi baseline yaitu -1 dan -2 . Pada baseline 1 peneliti akan memberikan tes tertulis pada siswa untu mencari tahu kemampuan membuat menulis puisi sebelum diberikan perlakuan sedangkan baseline 2 peneliti akan memberikan tes tertulis kembali pada siswa untu mendapatkan informasi terhadap kemampuan membuat menulis puisi setelah diberikan perlakuan baik pre-test dan post-test.

Teknik Pengumpulan Data

Tes merupakan teknik pengumpulan data dengan memberikan beberapa pernyataan guna mendapatkan informasi penelitian. Tes ini akan digunakan pada dua kondisi baseline yaitu 1 dan baseline 2 . Pada baseline 1 penelitian akan memberikan tes tertulis pada siswa untuk mencari tahu kemampuan membuat menulis puisi sebelum diberikan perlakuan sedangkan baseline 2 peneliti akan memberikan tes tertulis kembali pada siswa untuk mendapatkan informasi mengenai kemampuan membuat menulis puisi setelah diberikan perlakuan baik pre-test dan post-test.

Teknik Analisis Data

Teknik analisis data yang digunakan dalam penelitian ini adalah analisis data deskriptif dan inferensial. Secara deskriptif meliputi nilai maksimum, minimum, rata-rata, modus, standar deviasi, variansi. Sedangkan untuk analisis inferensial adalah uji hipotesis menggunakan uji t yaitu uji normalitas. Kemudian dilanjutukan lagi uji hipotesis.

\section{HASIL DAN PEMBAHASN HASIL PENELITIAN}

Penelitian ini dilaksanakan di SMK Negeri Bulo Kabupaten Polewali Mandar dengan sampel peelitian peserta didik kelas X APHP 1 sebagai kelas eksperimen dan kelas X APHP 2 sebagai kelas kontrol. pada prinsipnya, kedua kelompok ini dilaksanakan dua tahap kegiatan yaitu pembelajaran dan pemberian tes. Tes digunakan untuk mengetahui hasil hasil belajar peserta didik setelah mengikuti pembelajaran pada kelompok pembelajaran eksperimen digunakan metode outdoor learning, sedangkan pada kelompok kontrol tidak digunakan metode outdoor learning.

Pada kedua kelompok ini diberikan pada tes awal pre-test untuk mengetahui sejauh mana pendalaman materi yang telah dipelajari peserta didik dan pada akhir perlakuan kedua kelompok ini diberikan tes akhir post-test, dimana kelas eksperimen menggunakan metode outdoor learning.

\section{PEMBAHASAN}

Penelitian ini bertujuan mengetahui efektif pembelajaran bahasa indonesia pada peserta didik kelas X SMK Negeri Bulo, yaitu penelitian terhadap kemampuan menulis puisi dengan menggunanakn metode, populasi pada penelitia ini adalah seluruh kelas X SMK Negeri Bulo. Pemilihan sampel dilakukn secara acak sehingga diperoleh kelas X APHP 1 sebagai kelompok eksperimen dan kelas X APHP 2 sebagai kelas kontrol. untuk mengetahui kondisi awal kedua kelas tersebut, maka peneliti memberikan tes awal (pre-test) dengan soal yang sama kepada kelas eksperimen dan kontrol. untuk kelas X APHP 1 memperoleh nilai ratarata 56,80 kelas X APHP 2 memperoleh nilai rata-rata mean 55,20 . 
Selanjutnya dilakukan pengajaran dengan dengan memberikan perlakuan yang berbeda kepada kedua kelas yang ada. Perlakuan yang diberikan yaitu untuk kelas X APHP 1 sebagai kelas eksperimen diajar dengan menggunakan metode outdoor learning yang tidak bisa digunakan guru bahasa indonesia kelas X SMK Negeri Bulo dalam proses belajar mengajar sedangkan untu kelas X APHP 2 diajar tanpa perlakuan. Langkah berikutnya memberikan post-test yaitu tes hasil belajar tesebut dianalisis secara dsekriptif.

Hasil analisis deskriptif menunjukkan bahwa skor rata-rata hasil belajar peserta didik kelompok eksperimen yang diajar dengan metode pembelajaran dengan menggunakan metode outdoor learning (mendapatkan perlakuan) adalah 76,20 dari skor ideal 100 sedangkan hasil belajar peserta didik kelompok kontrol yang (tidak mendapatkan perlakuan) 67,96 dari skor ideal 100. Terlihat bahwa skor rata-rata hasil belajar peserta didik pada kelompok eksperimen lebih baik dari pada skor rata-rata hasil belajr kelompok kontrol.

Hasil analisis inferensial dengan menggunakan uji t menunjukkan bahwa hasil belajar bahasa indonesia peserta didik kelas X SMK Negeri Bulo yang menggunakan metode outdoor learning lebih tinggi dari pada hasil belajar peserta didik diajar dengan tidak dikenakan perlakuan.

\section{KESIMPULAN}

Berdasarkan hasil analisis data yang sudah didapatkan pada peenlitian ini, bisa untuk disimpulkan bahwa metode outdoor learning efektif terhadap pada kemampuan menulis puisi ssiwa kelas X SMK Negeri Bulo dan bisa lebih paham isi puisi. Hal ini dibuktikan dengan melihat perolehan rata-rata nilai yang diraih siswa kelas X APHP 1 berlaku sebagai kelompok eksperimen pada tes awal adalah 56 dalam kategori kurang mampu dengan tes akhir sebanyak 76,20 dengan menjalani peningkatan pada kategori bisa setelah dipakai metode outdoor learning efektif terhadap kemampuan menulis puisi sedangkan nilai rata-rata yang dicapai peserta didik kelas X APHP 2 yang bertindak selaku kelompok kontrol pada tes awal adalah 55 dalam kategori kurang mampu dan tes akhir 67 masih dalam kategori yang kurang mampu yang berarti tidak adanya efektif pada peserta didik SMK Negeri Bulo.

\section{SARAN}

Bersumber pada apa yang sudah peneliti lakukan selama proses penelitian, maka penulis mampu memberi saran atau arahan yang bertujuan pada peningkatan kualitas pengajaran supaya dicapai tujuan dari proses pembelajaran tersebut dianataranya:

Tabel dan gambar diletakkan di dalam kelompok teks. Format Century (9 pt) digunakan untuk menuliskan nomor urut, judul, serta teks dalam tabel dan gambar. Judul tabel ditulis rata kiri dan diletakkan di atas tabel yang bersangkutan. Judul gambar ditulis rata tengah dan diletakkan di bawah gambar yang bersangkutan. Gambar dan tabel harus dapat tercetak dengan jelas, diberikan rujukan dan keterangan singkatan jika diperlukan. Tabel dibuat tanpa garis vertikal, sedangkan garis horisontal ditampilkan untuk item judul kolom dan penutup di baris paling bawah.

1. Seorang guru harusnya lebih muda merasa pada metode belajar peserta didik sehingga guru seharusnya bisa lebih memiliki data cipta dalam menjalani macam-macam tujuannya agar terpenuhinya model model belajar gaya belajar siswa yang dibutuhkan walu banyak perbedaan akan tetapi bisa dicapainya tujuan dari pembelajaran tersebut.

2. Ketika belum melakukan pengajaran, baiknya seorang tenaga pengajar meransang kemauan dan semangat dalam belajar pada siswa supaya mereka akan bersemangat ketika menjalani prises pembelajaran

3. Seorang harusnya lebih mudah menerima saran dari luar, supaya pada kegiatan belajar mengajar yang dijalankan mampu terlaksana secara maksimal dan mampu diterima pada peserta didik dengan mudah atau gampang diterima

\section{DAFTAR PUSTAKA}

H. Alwi etc. (2001). Tata Bahasa Baku Bahasa Indonesia: Edisi Ketiga. Jakarta: Balai Pustaka

Mahsun, (2014). Teks dalam Pembelajaran Bahasa Indonesia Kurikulum 2013. Jakarta:Rajagrafindo Persad.

Muthmainnah, M. (2017). Drama Kemampuan Menulis Naskah melalui Pembelajaran Berbasis Otak Peserta Didik Kelas IX F SMP Negeri 2 Campalagian. Pepatudzu: Media Pendidikan dan Sosial Kemasyarakatan, 12 (1) , 63-74

Arikunto, (2010). Prosedur Penelitian Suatu Pendekatan Praktik. Jakarta: PT Rineka Cipta.

Tarigan. (2008). Menulis. Bandung: Angkasa

Kusumaningsih. Dewi. (2013). Terampil Berbahasa Indonesia. Yogyakarta : C.V ANDI OFFSET

Zainurrahman. (2011). Menulis dari Teori Hingga Praktik (Penawar Racun Plagiarisme). Bandung: Alfabeta. 